\title{
MENADŽMENT KAO FAKTOR NEUSPEŠNOSTI RESTRUKTURIRANJA PREDUZEĆA U SRBIJI
}

\author{
Lazo Kukobat ${ }^{1 \star}$, Marija Desivojević-Cvetković ${ }^{2}$, Biljana Jurišić ${ }^{3}$ \\ ${ }^{1}$ Frigobel, Kumodraška 398, Beograd, Srbija \\ ${ }^{2}$ Delta Holding, Milentija Popovića 7b, Beograd, Srbija \\ ${ }^{3}$ Magic Fruits Land, Palmira Toljatija 5/2, Beograd, Srbija
}

\begin{abstract}
Apstrakt:
Da bi kompanija bila uspešna na funkcionalnom i integrisanom tržištu, njen menadžment trebalo bi da bude u stanju da preduzme inicijativu, da bude kreativan i spreman za nove poduhvate. U periodu tranzicije i restrukturiranja, menadžment donosi važne poslovne odluke koje utiču ne samo na zaposlene, već i na šire okruženje. Cilj rada jeste da ukaže na značaj menadžmenta u sporom i neadekvatnom sprovođenju postupaka restrukturiranja nekada vodećih srpskih kompanija koje su masovno nestale sa domaćeg i inostranog tržišta. Danas u Republici Srbiji postoji oko pet stotina preduzeća čija je budućnost neizvesna, odnosno, najvećim delom vodi ka likvidaciji i uništenju istih. U radu se analizira (loš) rad menadžmenta u kompanijama gde su brzina i kvalitet za sprovođenje promena u organizaciji rada i poslovanja neophodni za dalji opstanak na tržištu. Tokom istraživanja dolazi se do zaključka o važnosti i značaju menadžmenta, koji ako je uspešan ima veći značaj od raspoloživih resursa, odnosno, intelektualni rad postaje presudan faktor za uspešan rad kompanija, dok se izvršne aktivnosti mahom preusmeravaju na inteligentne mašine i robote.
\end{abstract}

\author{
Ključne reči: \\ menadžment, \\ resursi, \\ likvidacija, \\ odluke.
}

\section{UVOD}

Deceniju i po zemlje srednje i istočne Evrope nalaze se u procesu postsocijalističke tranzicije. Ovaj proces je vrlo složen, pun neizvesnosti i mnogih teških društvenih lomova, a istorijska iskustva u ovim procesima ne postoje. Petnaestak godina procesa tranzicije dovoljno je dugo razdoblje za procenu rezultata. Dovoljno je samo ukazati na činjenicu da je osam postsocijalističkih zemalja uspešno prošlo prve dve etape tranzicije i sada ulaze u fazu konsolidacije, dok se druge zemlje (među kojima su sve novonastale države s prostora bivše SFRJ - osim Slovenije) mogu, za sada, smatrati gubitnicima ovih procesa. Tranzicijski i posleratni društveni procesi su rezultirali:
a) neefikasnom privredom,
b) velikim brojem nezaposlenih,
c) velikim unutrašnjim i inostranim dugovima,
d) velikim tehnološkim zaostatkom,
e) velikim migracijama $i$
f) osiromašenjem velikog dela stanovništva.

Sažeto rečeno - rezultirali su civilizacijskim zaostajanjem ovih zemalja i njihovih privreda za svojim srednjoevropskim okruženjem, odnosno, rezultirali su regresijskim procesima u odnosu na svoje ljudske i prirodne potencijale.

Preduzeća u Srbiji su prošla kroz takve promene i turbulencije, počev od raspada SFRJ, ratnih dešavanja, promena modela privatizacije, poslovanja u uslovima sankcija, do još uvek nestabilne političke situacije i budućnosti, da ih je i danas "teško dovesti u red". Poslovanje u periodu ekonomskih sankcija izrodilo je toliko negativnih poslovnih pojava do nivoa principa, do uslovljenog, ali i svesnog zaobilaženja zakona i propisa, kako u međunarodnom tako i u domaćem poslovanju. Jednom primenjena makijavelistička poslovna filozofija u interesu opšteg, vremenom dobija sve izraženije oblike i ličnog i onda se teško suzbija.

\section{RESTRUKTURIRANJE PREDUZEĆA I ULOGA MENADŽMENTA}

Padom Berlinskog zida krajem 1989. godine počeo je i jedan od najznačajnijih i najkompleksnijih procesa ekonomske tranzicije u istoriji ljudskog društva (Stiglic, 2004). Radi se o ekonomskim mehanizmima koji utiču na sam tok procesa tranzicije. Prema Blanchard-u (1997) to su:

1) realokacija-preusmeravanje resursa iz jednog $u$ drugi privredni sektor i

2) restrukturiranje-suštinska transformacija preduzeća da bi opstala u novim tržišnim uslovima privređivanja.

To se ne odnosi iskljucivo na promenu svojinskih odnosa, kroz proces privatizacije, nego i na njihovo poslovanje, strukturu i samu organizaciju rada i proizvodnje.

\subsection{Privatizacija}

Privatizacija predstavlja logičan korak ka tržišnoj ekonomiji i njenoj većoj efikasnosti, sa ciljem prelaska preduzeća u privatnu svojinu. Ona predstavlja samo metod tj. sredstvo da ekonomija postane efikasnija. Dobra strategija privatizacije posmatra upravljanje preduzećima i kao cilj, ali i kao sredstvo u toku postprivatizacionog restrukturiranja. Stoga, način privatizacije uslovljava vlasničku strukturu i karakter svojinskih odnosa, koji će nastati tokom i nakon privatizacije društvenog i državnog sektora, a ti svojinski odnosi definišu položaj 
akcionara, odnos snaga , način upravljanja u privatizovanim preduzećima itd.

Najveći broj preduzeća u srpskoj privredi, posebno velikih poslovnih sistema, zatečen je novonastalom situacijom tj. novim društveno-političkim i ekonomskim promenama, koje ubrzo počinju da im određuju dalji tok poslovanja. U takvim okolnostima preduzeća ulaze u proces privatizacije i restrukturiranja. Osnovni razlozi zbog kojih preduzeća podležu restrukturiranju, a zbog čega nisu privlačna ni potencijalnim kupcima su: prezaduženost, veliki tehnološki viškovi radnika u kombinaciji sa niskom produktivnošću, neadekvatna organizacija preduzeća i tehničko-tehnološka zastarelost sredstava. Dejstvo ovih faktora najčešće je kumulativno. Restrukturiranje se odvija pre, u toku i posle privatizacije. Menadžment se po prvi put susreće sa tržišnom ekonomijom koja zahteva hitne, neophodne i "bolne" promene u samom načinu poslovanja kao i u preduzeću. Neophodno je da se odrade krupne poslovne promene sa mnogim zaokretima u poslovanju koji su do tada bili nezamislivi, na primer, otpuštanje viška zaposlenih, povećanje produktivnosti rada, proizvodnja samo tržišno konkurentnog proizvoda, gašenje delova preduzeća itd. Mali broj društvenih i državnih preduzeća (Yuhor, Imlek, Frikom, Soko Štark) je restrukturiran posle uspešne privatizacije, koja se desila na vreme i od strane ambicioznih vlasnika, tako da je proces propadanja sprečen, a restrukturirana i moderna preduzeća su nastavila sa radom. Dok su većina neprivatizovanih preduzeća, na primer, Genex, Centrocoop, Trudbenik, Prokupac, Lola, Rekord itd., poslovno usporena, tehnološki zaostala, kadrovski skromna, neorganizovano ušla u proces tranzicije i restrukturiranja, utapajući se tako u sivilo društva i privrede devedesetih godina prošlog veka. Proizvodnja i trgovina su se postepeno smanjivale ili gotovo gasile, gubila su se tržišta, osipao se stručni kadar, dotrajala tehnika je otkazivala, a novca za novu opremu nije bilo. Višak zaposlenih je dodatno opterećivao preduzeća, ne samo finansijski nego i motivaciono, tako da je sa puno nezadovoljstva, apatije i nerada dolazilo do postepenog „umiranja” najvećih srpskih preduzeća (procesi stečaja i likvidacije).

Prema podacima Ministarstva privrede (2015), u portfoliju Agencije za privatizaciju je 526 subjekata privatizacije u Srbiji. Uprkos relativno čestim promenama pravnog okvira za privatizaciju tokom proteklih nekoliko godina, usmerenih na ubrzavanje i okončanje ovog postupka, evidentno je da privatizacija nije završena kvalitetno i na vreme. Ključni problemi, problemi viška radne snage, problemi nerešenih imovinsko-pravnih pitanja, problemi prezaduženosti, ostaju još uvek nerešeni. Usled nerešavanja imovinskih pitanja, viška radnika, visoke zaduženosti i kontinuiranog mekog budžetskog ograničenja, nastale su nove, negativne posledice (Radulović \& Dragutinović, 2014). Rizik kupovine preduzeća sa navedenim problemima doveo je do negativne selekcije investitora. Interes strateških investitora (ključne determinante uspešnosti privatizacije) koji bi izvrišili transfer tehnologije, preduzeli mere operativnog restrukturiranja i investirali u opremu bio je ograničen ka preduzećima koja su poslovala u izrazito profitabilnim sektorima ili preduzećima kod kojih imovinsko-pravni problemi i problemi sa zaposlenima nisu bili izraženi. Takvih preduzeća u Srbiji je bilo veoma malo. Srbija je kasnila u tranziciji, a veliki broj investitora već je investirao u regionu, tako da nisu bili zainteresovani za nova ulaganja. Upravljanje javnim prihodima i poštovanje propisa su osnova stabilnosti poslovnog okruženja.

Analiza pokazatelja opštih uslova poslovanja pokazuje da se Srbija u 2010. godini nalazi na 88 mestu na listi od 183 ze- mlje (The World Bank Group, 2009). Na prvom mestu se nalazi Singapur, a od razvijenih tranzicionih zemalja Slovačka ima najbolje uslove poslovanja. Slovačka se nalazi na 42, Bugarska na 44, Mađarska na 47, Rumunija na 55 i Grčka na 109 mestu prema uslovima poslovanja.

Poslovno okruženje (Radulović \& Dragutinović, 2014) je presudno pri donošenju odluka o investiranju kako u slučaju privatizacija, tako i u slučaju novih (grinfild) investicija. Iako je niz opština unapredilo svoje poslovno okruženje (Novi Beograd, Inđija, Jagodina), važno je napomenuti da postoje brojne mogućnosti za poboljšanje investiranja (takse, postojeća infrastruktura, kvalitet komunalnih usluga, naknade za građevinsko zemljište).

Nezavršena privatizacija i restrukturiranje preostalih društvenih preduzeća, velikih javnih preduzeća i infrastrukturnih delatnosti, nedovoljno efikasan proces likvidacije i stečaja, ali i nedovoljno podsticanje postprivatizacionog restrukturiranja ključna su ograničenja za razvoj nove i efikasnije privredne strukture. Nažalost, privatizacija nije u dovoljnoj meri doprinela privrednom razvoju i novom zapošljavanju. Nova radna mesta su otvarana uglavnom u sektorima čiji proizvodi nisu izvozni (poslovi sa nekrtninama, iznajmljivanje, finansijsko posredovanje).

\subsection{Menadžment}

$\mathrm{Za}$ ostvarenje neophodnih promena u poslovanju preduzeća (kompanija) logičan odgovor se traži i u ponašanju menadžmenta koji mora da bude transformacioni lider, odnosno, da ima sposobnost kreiranja vizije, misije, ciljeva, politike i strategije i njihove implementacije, postižući pritom i krupne transformacione zaokrete u kratkom roku koji su usmereni isključivo ka tržišnom načinu poslovanja. Menadžment treba da se orijentiše prema ciljevima preduzeća. Cilj menadžmenta (Todorović, Đuričin i Janošević, 1998) je ostvarenje željenog stanja konkretne organizacije. Upravljanje vrednošću preduzeća je fiducijarna odgovornost menadžera, radi se o veoma delikatnom poslu. Takođe, preduzeće ne postoji da bi se obezbeđivala radna mesta, odgovaralo željama potrošača, uvećavalo veličinu (stepen) diversifikacije, primenjivalo nove tehnologije ili ostvarivalo druge ciljeve koji nisu u vezi sa ekonomičnim korišćenjem kapitala i uvećavanjem vrednosti. Zbog uvećanja vrednosti se retki rasursi usmeravaju u najpropulzivniju upotrebu, ali i prema najefektnijim korisnicima.

Menadžment u srpskoj privredi spada u retke u svetu, koji i pored značajnih promena koje su se desile u svetu pa i u Srbiji, nije zaživeo. Analizom prakse i putem parcijalnih istraživanja koja su rađena za potrebe određenih državnih organa, privrednih komora i dr., dolazi se do zaključka, da Srbija nema ni izdaleka kvalitetan i uspešan menadžment i da nedovoljno čini da on bude na nivou zemalja razvijenih tržišnih ekonomija (Radosavljević \& Tomić, 2007).

Tokom perioda tranzicije i privatizacije koji u Srbiji traje već četvrt veka menadžment većine kompanija nije odgovorio svojim novopostavljenim zadacima u meri u kojoj se od njega očekivalo, a to je da preduzeća sačuvaju od propadanja ili gašenja i usmere ih ka tržišnom poslovanju putem restrukturiranja. Srpski menadžment nije školovan za upravljanje preduzećima, nije školovan da deluje u preduzetničkoj i turbulentnoj atmosferi kakve su uglavnom u okolini i svetu. Najčešće slabosti srpskog menadžmenta (Radosavljević \& Tomić, 2007) a koje potvrđuju izrečene konstatacije su: 
1) Menadžment se još uvek shvata kao funkcija - zaboravlja se da je to zanat koji ima svoje zakonitosti, algoritme i pravila ponašanja;

2) U Srbiji ne postoji dovoljno kvalitetnih visokih škola za upravljanje - još uvek važi pravilo da menadžerske i direktorske pozicije može da obavlja bilo ko od KV radnika do doktora nauka, naročito je prisutna tzv. politička podobnost što dovodi do toga da je menadžment u najvećem delu neprofesionalizovan;

3) Nedostatak menadžerske literature - menadžersko znanje se ne nalazi u knjigama, već u stručnim časopisima i internet literaturi zbog toga što časopisi i internet najčešće govore šta je bilo juče, a šta treba preduzeti već danas i sutra. Kod knjiga nije taj slučaj, često su zastareli izvori znanja.

Analiza, kroz dijagnosticiranje postojećeg stanja u srpskoj privredi, pokazuje da u Srbiji nema kvalitetnog menadžmenta već je još uvek politiziran i ideologiziran. Takođe, obiluje se sa nadovoljno obrazovanim i neprofesionalnim menadžerskim kadrom naročito u javnim i državnim preduzećima. Politički poslušnici i sledbenici uglavnom su imenovani na funkcije menadžera da bi zauzvrat delom investirali u fondove svojih političkih partija. Nasuprot srpskom menadžmentu, menadžment razvijenih tržišnih ekonomija karakteriše profesionalizam ogledan kroz stručnost, autonomnost i objektivnost, poštenje i status menadžera - plate, privilegije, kodeks kulture i ponašanja. „Polazište istraživanja i određenje kompetencije, kao temeljne karakteristike osobe, koja rezultira u uspešnom ili superiornom obavljanju poslova”. To može biti osobina ličnosti, motiv postizanja ciljeva, struktura znanja, veštine itd. (Tarrington, 1999). Ovo saznanje je značajno jer stvara branu da se poslovima upravljanja može baviti svako. Njegova efikasnost je uslovljena nivoom raspoloživog znanja i efikasne primene tehnike i alata koji su mu na raspolaganju (Radosavljević, 2008). Kada deluje nauka u isto vreme mora delovati i veština, što ukazuje da su ovo dve strane istog problema.

Menadžeri kroz znanje i naučne institucije ostvarivanju svoje ciljeve. To su eksperti za upravljanje pre svega ljudskim, ali i ostalim resursima. Zbog svoje stručnosti bolje upravljaju od vlasnika, a vlasnici njihovu efikasnost ocenjuju po profitu. Umesto ideologije propagiraju biznis. Suprotno iznetom, srpski menadžment je u najvećem delu propustio priliku da tokom dosadašnje tranzicije, putem privatizacije i neopravdano dugog restrukturiranja velikog broja preduzeća, napravi strateški važne i hrabre poslovne poteze koji bi rezultirali očuvanju većeg broja preduzeća čija bi proizvodnja isključivo bila usmerena ka tržišno konkurentnim i izvozno orijentisanim proizvodima.

\section{REZIME}

Restrukturiranje srpskih kompanija, tokom poslednjih četvrt veka, teče dosta sporo i po mnogim pokazateljima neuspešno, što pokazuju i podaci Agencije za privatizaciju o broju preduzeća koja su još u privatizaciji i broju preduzeća u aktivnom stečajnom postupku. Gotovo hiljadu preduzeća su ili nelikvidna ili posluju na ivici likvidnosti. Pored opših uslova poslovanja, po kojima Srbija ne spada u zemlje iz gornjeg dela tabele, srpski menadžment, predstavlja jedan od faktora neuspeha pravovremenog i uspešnog restrukturiranja većine domaćih preduzeća. Menadžment srpskih preduzeća u najvećem delu nije bio kompetentan za sferu upravljanja preduzećima. Umesto brzih promena i prilagođavanja novonastaloj situaciji, kako bi se preduzeća što pre finansijski oporavljala i stasavala za novu tržišnu utakmicu, domaći menadžment kao neprofesionalan, politički podoban, ideologiziran, priučen za birokratsko upravljanje ljudima i bitisanje u birokratskoj mirnoj organizaciji, nije bio sposoban i školovan da deluje u preduzetničkoj i turbulentnoj organizaciji kakve postoje u razvijenim tržišnim ekonomijama. Na kraju, može se konstatovati da Srbija nema kvalitetan menadžment i da nedovoljno čini da on bude na nivou savremenosti.

\section{LITERATURA}

Blanchard, O. (1997). The Economics of Post-Communist Transition. Oxford: Clarendon Press.

FREN. (2010). Postkrizni model ekonomskog razvoja i rasta Srbije 2011-2020. Beograd: FREN. Preuzeto 1. novembra 2015. sa http://www.fren.org.rs/node/120

Ministarstvo privrede Republike Srbije. (2015). Privatizacija. Preuzeto 1. novembra 2015. sa http://www.privreda.gov.rs/privatizacija/

Radosavljević, Ž., \& Tomić, R. (2007). Menadžment u modernom biznisu. Novi Sad: Privredna akademija.

Radosavljević, Ž. (2008). Menadžment znanja i(li) znanje u menadžmentu. Beograd: Centar za edukaciju rukovodećih kadrova i konsalting.

Radulović, B., \& Dragutinović, S. (2014). Privatizacija u Srbiji: studija slučaja. Beograd: NALED.

Stiglic, Dž. E. (2004). Protivrecnosti globalizacije. Beograd: SBM-x.

Tarrington, D. (1999). Personnel Management: A new approach (str. 408-410). UK: Prentice Hall International

Todorović, J., Đuričin, D., \& Janošević, S. (1998). Strategijski menadžment. Beograd: Institut za tržišna istraživanja.

World Bank Group. (2009). Doing business 2009. Preuzeto 1. novembra 2015. sa http://www.doingbusiness.org/reports/ global-reports/doing-business-2009/

World Bank Group. (2010). Doing business 2010. Preuzeto 1. novembra 2015. sa http://www.doingbusiness.org/reports/ global-reports/doing-business-2010/

\section{MANAGEMENT AS A FACTOR OF FAILURE IN RESTRUCTURING OF SERBIAN COMPANIES}

\begin{abstract}
:
In order for an enterprise to operate successfully on the functional and integrated market, its management should be willing to take initiative, and to be creative and ready for new ventures. In particular, during the period of transition and restructuring, the management of an enterprise makes important business decisions that affect not only its employees, but also the wider community. The purpose of the paper is to highlight the importance of management in slow and inadequate implementation of the restructuring procedures of the former leading Serbian companies that have disappeared from the domestic and foreign markets. There are currently nearly five hundred companies on the territory of the Republic of Serbia whose future is uncertain; i.e. it mostly leads to their liquidation. The paper analyzes the (bad) work of management in the companies where the speed and the quality to implement changes to organization and operations are necessary for the company's survival in the market. The research herein conducted leads to the conclusion on the importance of management, as successful management becomes more important than resources available, i.e. intellectual work becomes a crucial factor for the success of companies, while operations are largely shifting to intelligent machines and robots.
\end{abstract}

\section{Key words:}

management,

resources,

liquidation,

decisions. 